\title{
Um aplicativo mobile para auxiliar a Gestão de Riscos no Brasil: lições aprendidas em uma perspectiva sociotécnica
}

\author{
Ana Luiza Ferreira Figueiredo ${ }^{1}$, Flávio Horita ${ }^{1}$
}

\author{
${ }^{1}$ Universidade Federal do ABC \\ Av. dos Estados, 5001 - Bangú, Santo André - SP, 09210-580 \\ ana.figueiredo@aluno.ufabc.edu.br, flavio.horita@ufabc.edu.br
}

\begin{abstract}
Mapping of areas susceptible to geological risks requires updated geological and structural data. The data collection process is slow and ineffective, due to the lack of proper technological tools. A mobile app is being developed to meet this need. This article discusses its development process and the methodologies adopted in light of the concept of "sociotechnical approach".
\end{abstract}

Resumo. O mapeamento de áreas vulneráveis a riscos geológicos requer dados geológico-estruturais atualizados. O processo de coleta e análise de dados observado é lento e pouco eficaz, devido à falta de mecanismos tecnológicos apropriados. Está sendo desenvolvido um aplicativo mobile para suprir essa necessidade. Este artigo discute, a partir do conceito de abordagem sociotécnica, seu processo de desenvolvimento e as metodologias adotadas.

\section{Introdução}

Segundo [Macedo 2011], a análise de risco considera uma combinação de três elementos: tipologia do processo esperado (como inundações e deslizamentos) e sua probabilidade de ocorrência; vulnerabilidade de assentamentos urbanos; e potencial dano à uma comunidade exposta. Atualmente, tal análise apresenta falhas no que tange seu processo de coleta e estudos dos dados pois esses são coletados pelos profissionais da área durante visitas de campo e preenchidos de forma manuscrita em uma ficha. Perdas de fichas, preenchimento ilegível ou incompleto comprometem a qualidade dos dados coletados.

Este artigo tem como objetivo apresentar os esforços na elaboração de um aplicativo mobile para suprir as falhas do atual método de coleta de dados. Dentre suas premissas, o aplicativo deve suportar a instalação em sistemas operacionais Android ou iOS. Para isso, um laboratório de gestão de riscos de uma universidade pública foi adotado como caso prático, pois apoia a elaboração do Plano Municipal de Redução de Risco (PMRR) em municípios da Grande São Paulo. Além disso, este caso é interessante porque compreende a coleta de dados por meio do mapeamento e estudo de áreas de riscos (i.e., geológicos e construtivos) adaptando a metodologia publicada pelo Ministério das Cidades em parceria com o Instituto de Pesquisas Tecnológicas (IPT) [Macedo 2011, Smith and Jones 2007].

Assim, o trabalho busca resolver três problemas existentes na literatura e prática: 1) automatizar o processo de coleta de dados em campo com base na metodologia proposta pelo IPT; 2) apresentar um aplicativo para apoiar e implementar essa automatização; e 3) realizar um estudo sociotécnico no cenário de aplicação. Desta forma, além da contribuição tecnológica-prática (i.e., o projeto do aplicativo), este artigo também traz 
luz aos Grandes Desafios de Pesquisa em SI 2016-2026, em particular, ao desafio "Visão Sociotécnica dos Sistemas de Informação" [Cafezeiro et al. 2017].

\section{Contextualização Teórica: Aplicativos para Gestão de Desastres}

No que abrange a gestão de riscos há uma variedade de aplicativos desenvolvidos pela comunidade acadêmica e prática. Dentre eles, o aplicativo proposto por [Lima et al. 2018] emite alertas em situações de risco imediato por meio da análise de dados fornecidos por moradores locais. Já o Sistema de Informação para Cadastro das Áreas de Deslizamento de Solo, Enchentes e Inundação ("SICADSEI") [dos Santos et al. 2012] é similar ao aplicativo ora proposto, porém baseado em Web. Observa-se a falta de aplicativos voltados à coleta de dados por especialistas em campo, onde muitas vezes não há acesso à internet.

\section{Abordagem Metodológica}

Este projeto adotou uma abordagem metodológica baseada em ciclos interativos de co-projeto de artefatos (aqui, o aplicativo móvel) em que o cientista da computação e os membros das equipes de gestão do risco discutiam os resultados obtidos e os próximos passos. Esta abordagem é melhor explicada e detalhada em artigo anterior [Figueiredo et al. 2019] e foi definida com base na perspectiva sociotécnica [Cafezeiro et al. 2017], apoiada no entralaçamento entre os saberes técnicos e teoricos das áreas da computação e da gestão de riscos no Brasil.

Tabela 1. Ciclos da modelagem do aplicativo

\begin{tabular}{|c|l|l|}
\hline Ciclos & \multicolumn{1}{|c|}{ Período } & \multicolumn{1}{|c|}{ Atividades } \\
\hline 1 & Abril/2018 & $\begin{array}{l}\text { Acompanhamento em trabalho de campo do } \\
\text { Laboratório de Gestão de Riscos. }\end{array}$ \\
\hline 2 & Agosto a Novembro/2018 & $\begin{array}{l}\text { Levantamento e validação dos requisitos junto ao } \\
\text { Laboratório de Gestão de Riscos. Protótipo de } \\
\text { interfaces. }\end{array}$ \\
\hline 3 & Janeiro a Fevereiro/2019 & $\begin{array}{l}\text { Avaliação do protótipo. Refinamento dos requisitos } \\
\text { com base nos dados do Ciclo 2. }\end{array}$ \\
\hline 4 & Março/2019 & Inclusão de novas interfaces \\
\hline 5 & Agosto/2019 & Implementação do BackEnd do aplicativo. \\
\hline
\end{tabular}

Para garantir a relevância do aplicativo, todos os ciclos contaram com a seguinte forma de abordagem: a cada nova atualização e avanço da modelagem, as informações obtidas eram validadas junto ao laboratório. Esse processo de co-projeto (i.e., o sistema usuário-ambiente envolvido em todo o processo de design [Cafezeiro et al. 2017]) envolveu a criação de um protótipo interativo de telas, que permitiu identificar diferenças entre o comportamento ideal e real do usuário em relação ao sistema desenvolvido. Assim, a usabilidade do protótipo foi refinada, no Ciclo 4. Após o projeto do aplicativo, este foi implementado na camada atribuída ao servidor onde a linguagem de programação Java foi adotada. Enquanto, no que tange ao armazenamento de dados coletados, o banco de dados MySQL foi empregado e como tratamento utilizamos o framework Hibernate.

\section{Resultados e Discussões}

No que tange a contribuição tecnológica, ou seja, o aplicativo mobile, as Figuras 1a e 1b apresentam, da esquerda para a direita, o modelo de dados e a evolução dos protótipos de tela após os ciclos. 


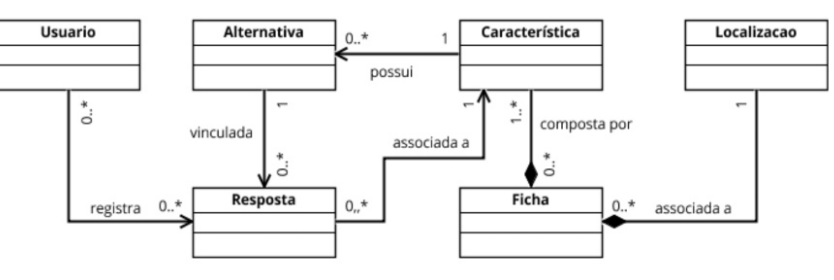

(a) Modelo de Dados

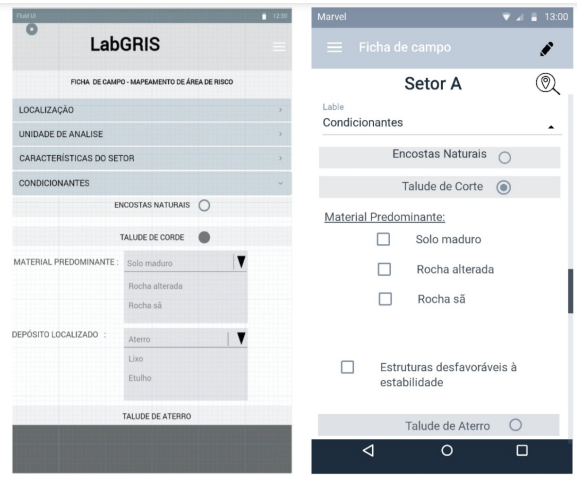

(b) Interfaces

Figura 1. Artefatos do Aplicativo Mobile

De maneira geral, o modelo de dados elaborado busca tornar flexível a configuração dos dados a serem coletados pelas relações definidas entre as entidades Característica-Alternativa-Resposta. Isto possibilita ao gestor cadastrar quantas características de análise ele desejar.

Com relação à abordagem metodológica, diversas foram as lições aprendidas a partir do co-projeto do aplicativo. Em primeiro lugar, o envolvimento de membros da área prática (i.e., os membros do laboratório de risco) no projeto do aplicativo tornou mais fácil a compreensão das necessidades e dificuldades a serem atendidas. Essas observações foram reforçadas pela visita de campo realizada no Ciclo 1, o qual também serviu para compreender o contexto em que se daria o uso do aplicativo e identificar novas necessidades não detalhadas pelos membros da prática; e.g., o armazenamento local de dados visando sua sincronização a posteriori. Segundo, os membros da prática foram entrevistados para que o conhecimento adquirido fosse refinado e derivado em requisitos do aplicativo. Interessante mencionar que diferente de uma atividade de levantamento de requisitos normal, o co-projeto demanda um comprometimento muito maior dos membros da prática para com o projeto; caso contrário, falhas e mal-entendidos podem acontecer ao longo do processo.

Por fim, a visão sociotécnica em que o trabalho deve ser realizado "com a sociedade" de fato melhora os resultados de pesquisa e prática. Dessa forma, os ciclos promovidos pela abordagem metodológica deste trabalho aproximaram o desenvolvimento do aplicativo de seu contexto real, i.e., próximo de seu domínio de conhecimento, mas, ao mesmo tempo, sob as diversas perspectiva de análise (e.g., computação, planejamento territorial e gestão de desastres). Ainda neste contexto, este trabalho não se manteve intrinsecamente atrelado a alguma metodologia de desenvolvimento de software previamente desenvolvida. Procurou-se então, entender e se adaptar às necessidades dos futuros usuários, bem como compreender os ambientes onde o sistema seria utilizado, como descrito por [Cafezeiro et al. 2017].

\section{Conclusões}

Os resultados alcançados mostram que o aplicativo em desenvolvimento é interessante para a área de aplicação, mas também mostra os grandes benefícios atrelados a adoção de uma abordagem sociotécnica na prática e na pesquisa. 
A abordagem sociotécnica permitiu a elaboração de novas funcionalidades que diferenciam este projeto das ferrramentas já existentes citadas acima. Algumas dessas diferenças são: o uso da ferramenta é destinado exclusivamente para que especialistas da área possam coletar dados e não deve ser usado para emissão de alertas, diferentemente do proposto por [Lima et al. 2018]; o aplicativo poderá ser carregado e salvará os dados mesmo sem acesso à internet; além disso, terá alternativas condiciondas às respostas anteriores, o que diminui a incidência de alternativas marcadas incorretamente, otimiza e torna mais limpa a visualização da tela, funcionalidades essas não presentes no SICADSEI [dos Santos et al. 2012].

Trabalhos futuros irão manter a abordagem sociotécnica, utilizada até o momento, de maneira a garantir o contínuo refinamento do aplicativo.

\section{Agradecimentos}

Os autores agradecem ao apoio financeiro do Conselho Nacional de Desenvolvimento Científico e Tecnológico (CNPq), Processo Nro 437937/2018-6.

\section{Referências}

Cafezeiro, I., Viterbo, J., da Costa, L. C., Salgado, L., Rocha, M., and Monteiro, R. S. (2017). Strengthening of the sociotechnical approach in information systems research. I GranDSI-BR — Grand Research Challenges in IS in Brazil - 2016-2026.

dos Santos, A. R., Magalhães, I. A. L., Ferrari, J. L., Moreira, T. R., Dalfi, R. L., de Campos, R. F., Eugenio, F. C., Junior, E. R. A., Silva, A. C., and Pimenta, A. A. G. (2012). O software SICADSEI 1.0 e suas aplicações como sistema de informação para cadastro das áreas de deslizamento de solo, enchentes e inundação. Engenharia Ambiental: Pesquisa e Tecnologia.

Figueiredo, A. L. F., Inocêncio, T. J., Gonzales, G. R., and Horita, F. E. A. (2019). Projeto de um aplicativo mobile para a coleta estruturada de dados e mapeamento de áreas suscetíveis a riscos geológicos. pages 172-175. 10 Workshop de Computação Aplicada a Gestão do Meio Ambiente e Recursos Naturais (WCAMA).

Lima, A. S. A., Schmidt, A. E. F., Nogueira, R. R., and de Oliveira, P. C. F. (2018). Aplicativo colaborativo para alerta de vulnerabilidade a alagamentos e enchentes no vale do itajaí. $9^{\circ}$ Workshop de Computação Aplicada à Gestão do Meio Ambiente e Recursos Naturais (WCAMA CSBC 2018).

Macedo, E. (2011). Methodological procedures to landslide risk mapping in brazilian slums. Proceedings of the Second World Landslide Forum, Rome, Itália.

Smith, A. and Jones, B. (2007). Mapeamento de riscos em encostas e margem de rios. Ministério Das Cidades / Instituto De Pesquisas Tecnológicas - IPT. 